\title{
Costing the impact of climate change on tourism in Europe: results of the PESETA project
}

\author{
Bas Amelung • Alvaro Moreno
}

Received: 8 April 2010/Accepted: 8 September 2011 /Published online: 25 November 2011

C The Author(s) 2011. This article is published with open access at Springerlink.com

\begin{abstract}
Climate change might lead to large shifts in tourist flows, with large economic implications. This article simulates the effect of future climate change by the 2080 s on outdoor international tourism expenditure within Europe. The assessment is based on the statistical relationship between bed nights and a climate-related index of human comfort, after accounting for other determinants of bed nights such as income and prices. It is concluded that climate change could have significant impacts on the regional distribution of the physical resources supporting tourism in Europe. For example, in summer, Southern Europe could experience climate conditions that are less favourable to tourism than the current climate, while countries in the North could enjoy better conditions. The economic effects of these changes are likely to be sizeable, albeit difficult to assess. Crucially, they are shown to depend on tourists' temporal flexibility with respect to holiday planning. The greater the prominence of institutional rigidities such as school holidays, the larger the differences between winning and losing regions in terms of economic impact.
\end{abstract}

\section{Introduction}

Tourism is one of Europe's largest sectors, and Europe is the world's leading continent in terms of arrivals. Within Europe, there is a large annual flow of tourists from the northern half of Europe to the southern half (Todd 2003). A key factor in explaining this annual movement is climate. Many tourists are in search of sun, sea and sand, and an enjoyable climate, and prefer destinations that can reputably provide these features with a certain reliability, such as the Mediterranean. Clearly, an attractive and reliable climate is not a key attraction of all destinations; however, weather conditions do influence the choice of tourist activities on a

B. Amelung $\cdot$ A. Moreno

International Centre for Integrated assessment and Sustainable development (ICIS),

Maastricht University, P.O. box 616, 6200 MD Maastricht, The Netherlands

B. Amelung $(\square)$

Environmental Systems Analysis group, Wageningen University, P.O. box 47, 6700 AA Wageningen,

The Netherlands

e-mail: bas.amelung@wur.nl 
day-to-day basis almost everywhere. As a result, tourism is a multi-billion euro industry that is highly dependent on climate resources, and potentially sensitive to change.

Climate change may provoke shifts in tourist flows, with large economic implications. Higham and Hall (2005) identified climate change as the number one challenge to tourism in the 21st century. In the Fourth Assessment Report of the IPCC, tourism had considerably more prominence than in the previous assessments (Amelung et al. 2008), although the sector still does not receive the attention it merits based on its economic importance. Climate change will impact tourism in many different ways, as different types of tourism and tourist activities have different weather and climate requirements. Baseline information on these requirements is far from complete. In fact, the study of current relationships between weather, climate and tourism has gained renewed attention only recently, as the interest in the potential impact of climate change on tourism is growing (for an overview, see UNWTO-UNEP-WMO, 2008). A bottom-up approach to the evaluation of the impact of climate change on tourism in Europe is therefore only possible to a limited extent. Two major tourism segments for which previous studies exist and that are also among the most climate-dependent and climate change sensitive ones are light outdoor activities (including beach tourism), and winter sports. For winter sports, detailed studies and monetary estimates are already available (e.g. Agrawala 2007). These studies were reviewed in the PESETA project, but the main focus was on light outdoor tourism activities. The results that are reported in this paper also pertain to this latter market segment.

This study improves on earlier work by integrating two strands of work in the literature on climate change impacts on tourism. The first of these strands approaches the issue from the climate side, using observed and projected climate data to calculate (changes in) climatic attractiveness for tourism purposes. An early example of this type of study was the report by Rotmans et al. (1994) who employed the Hatch Index to assess the impact of climate change on tourism in Europe, calculating index values with simulated climate data from general circulation models (GCMs). Scott et al. (2004) applied the Tourist climatic index (TCI) to assess the current and future spatial and temporal distribution of climate resources for tourism in North America. Other TCI analyses exist for the Mediterranean (Amelung and Viner 2006), Northwestern Europe (Nicholls and Amelung 2008), and the whole world (Amelung et al. 2007). The general conclusion is that climate change will lower the suitability of equatorial regions for tourism, while improving the suitability of areas that are relatively close to the poles. The areas in between, such as the Mediterranean, the United States, South Africa and Japan will face mixed results, with TCI scores improving in one or several seasons and deteriorating in others. Strong features of this research strand are the level of spatial and temporal detail it can produce, and its moderate sophistication in representing climatic suitability for tourism, including thermal, physical, as well as aesthetic factors, as proposed by De Freitas (1990). The approach has been criticized for being subjective, and for the lack of empirical testing (De Freitas et al. 2008).

The second of the strands of research starts from the economic side. It attempts to introduce climate factors into tourism demand models. Over the years, a number of such models have been developed (Hamilton et al. 2005; Lise and Tol 2002; Maddison 2001). In general, these models arrive at much smaller impacts of climate change than the index-based studies. Two factors appear to be of particular importance for explaining this difference. First of all, the economic models take into account economic growth. Even in scenarios with relatively modest (but positive) growth rates, economic development drives the system in the longer term, dwarfing almost any change in climate conditions. Index-based studies are limited to climatic suitability.

Secondly, countries have typically been the basic unit of analysis, for which climate is represented by average annual temperature. This type of approach facilitates empirical 
validation against recorded visitor numbers. It also matches the spatial and temporal resolutions of most demand models as well as the resolutions of the best available data. For many countries, information about arrivals and other tourism variables is simply not available at higher resolutions. An important downside, however, is that tourism in fact is characterized by strong concentration both in space and time, a feature that cannot be captured by the models. All regional variation is lost, which is a major drawback for large countries, and, even more importantly, seasonal variation is ignored. Climate change may lead to changes in climatic seasonality. This is crucial, because time is of the essence in tourism. To give an example: for many people, school holidays represent the 'window of opportunity' for planning holiday activities. The demand models discussed above assume temporal indifference among tourists, which may be another important cause of their low estimates of the effects that climate change will have on the tourist industry, relative to factors such as economic development and population growth (Hamilton et al. 2005).

The PESETA study (Ciscar et al. 2009; 2011) combined the two lines of research, by constructing a tourism demand model, or rather a demand distribution model, using monthly, regional data. In doing so, the spatial and temporal detail of the index-based approach could be merged with the empirical validation of the economic-modelling approach. With the resulting model, the economic consequences of a range of climate change impacts were explored, including the effect of changing climatic suitabilities on the total number of arrivals in Europe, and potential temporal and geographical shifts in arrival patterns. The structure of this paper is as follows. Section 2 describes the methodology and data that were used. The assessment of the physical impacts of climate change is presented in section 3. Section 4 details the economic implications of the physical impacts. A discussion of the results and conclusions is in section 5 .

\section{Methodology and data}

Following the general guidelines of the PESETA project, the analysis was split up into two broad steps. The first step encompassed the estimation of historical and future climatic suitabilities for tourism. This first phase was termed physical assessment. In the second phase, past and future arrival patterns were estimated based on the climatic suitabilities produced by phase one, and economic implications were inferred from these patterns. This second phase was termed economic assessment.

In the context of this study, the suitability of a particular climate for tourism was represented by the Tourism Climatic Index (TCI), an index specifically developed for tourism by Mieczkowski (1985). It is based on the notion of "human comfort," and consists of five sub-indices, each represented by 1 or 2 monthly climate variables. The five subindices and their constituent variables are as follows: (i) daytime comfort index (maximum daily temperature (in ${ }^{\circ} \mathrm{C}$ ) and minimum daily relative humidity (\%)); (ii) daily comfort index (mean daily temperature $\left({ }^{\circ} \mathrm{C}\right)$ and mean daily relative humidity (\%)); (iii) precipitation (total precipitation, in $\mathrm{mm}$ ); (iv) sunshine (total hours of sunshine); and (iv) wind (average wind speed, in $\mathrm{m} / \mathrm{s}$ or $\mathrm{km} / \mathrm{h}$ ). The index is calculated as follows:

$$
T C I=2 C I D+8 C I A+4 R+4 S+2 W
$$

where $C I D$ daytime comfort index, $C I A$ daily comfort index, $R$ precipitation, $S$ sunshine, and $W$ wind speed. With an optimal rating for each variable of 5 , the maximum value of the index is 100 . 
All sub-indices are calculated with mean monthly values. The thermal comfort indices are based on effective temperature, which is a measure of temperature that takes the effect of relative humidity into account. The wind sub-index combines information about wind speed and temperature. The other indices are based on single variables and reflect either the empirical findings of physiological research or qualitative assessments of tourist preferences. For a detailed description of the set of variables, see Mieczkowski (1985).

Using the TCI, climate suitabilities were calculated for the baseline period of 1961-1990 and for the future periods of 2011-2040 and 2071-2100. The climate data needed for these calculations come from the PRUDENCE project (Christensen and Christensen 2007). To maximize consistency between the sectoral analyses in the PESETA project, all analyses were based on the same socio-economic and climate scenarios (see for more details Christensen et al. this issue). The climate scenarios were selected based on a number of criteria, including scientific credibility, availability, and spatial and temporal resolution. At the time of the start of the PESETA project, the largest and most consistent set of regional climate model output was available through the PRUDENCE project. Underlying the PESETA analyses were simulations with two models from the PRUDENCE collection: RCAO and HIRHAM. As no simulations for the 2011-2040 period were available for these models, while these were required for the PESETA project, output from the RCA3 model was added to the dataset. The SRES A2 and B2 socio-economic scenarios, developed by the IPCC, were selected to 'drive' the climate models, as they are partly representative of the full range of scenarios considered by the IPCC, and appropriate climate model output was available for them. The A2 scenario represents a path towards a 'high' concentration of greenhouse gases in the atmosphere, whereas the B2 scenario represents a path towards a 'low' concentration. The gridded data produced by these models was converted to individual regions at the NUTS 2 level for inclusion in the regression analysis.

The final aim of the endeavour was to model tourist activity, to estimate the role of climate, and to explore the effects of climate change. The changes in visitation patterns were explored in two steps. First a visitation model was estimated, based on historical data. Subsequently, the baseline and future scenarios were simulated. The historical visitation model was developed using regression techniques.

There are various indicators available for tourist visitation. The two main ones are arrivals and bed nights. An important advantage of using the number of bed nights is that it gives a better idea of tourist volumes than arrivals, as this latter indicator does not differentiate between, say, a 1-day and a 20-day visit. An important disadvantage of using the number of bed nights as an indicator is that there appear to be large differences between countries either in the quality of reporting or in the use that tourists make of formal establishments for accommodation. In particular in some of the new member states, the number of arrivals seems completely out of sync with the number of bed nights reported. However, there are also known problems with methodologies used for calculating arrivals, although the reliability of arrival data may be somewhat higher. Given the value of having insight into tourist volumes, we chose to use the number of bed nights, consumed by international visitors.

Information on the number of bed nights for NUTS 2 regions was available on an annual basis only. To arrive at monthly values, we used the information on the monthly split in visitation that was available at the country level. So, for example, if $4.5 \%$ of tourists visited a particular country in January, the number of bed nights in that month in each of the NUTS 2 regions was calculated by multiplying the region's annual number of bed nights by $4.5 \%$. For countries in which there are regions with very different seasonal distributions of tourists, this step may be problematic. 
To construct the model, a linear regression analysis was performed with the number of bed nights as the dependent variable. A range of possible independent variables was considered: TCI, income level, price index of hotel and restaurant services, the months of the year, etc. The source of income and price index data was Eurostat. The TCI scores varied per month to represent climatic seasonality. In addition, the months of the year were inserted as dummy variables to represent institutional seasonality. Price index values were available and used at the NUTS 2 level, whereas income was treated at country level.

Separate equations were estimated for the two control periods of the TCI datasets: one for the RCAO-based dataset and one for the HIRHAM-based dataset. The key result of the regression analysis was the TCI elasticity. With this elasticity value, the implications of changing climatic conditions for the visitation patterns in Europe could be projected. These changes in visitation were subsequently converted into changes in expenditure, by multiplying the number of bed nights by the amount of expenditure per bed night. Ideally, an economic assessment should be about changes in value added, rather than expenditure, but given the limited data availability and the lack of information about income multiplier in the different countries and regions, working with plain expenditure figures was the best achievable option. As a result, the assessment of the changes in visitation patterns is the key component of the economic analysis.

Needless to say, the climate is not the only factor that is changing. It is impossible to know what society will look like in a few decades from now, let alone at the end of the century. The use of scenarios can help shed some light on the range of uncertainties present, but there are very few long-term scenarios available for tourism. For the projections and scenarios that are available, their compatibility and consistency with the climate scenarios used for the PESETA project are unclear.

The task for PESETA was not to develop future scenarios for tourism, but to explore the economic implications of climate change for tourism development in Europe. Concluding that any assumption about the future development of determining variables other than climate is equally arbitrary, we decided to assess the impact of climate change by varying the value of the TCI variable in the equations according to the climate scenarios, and leaving all other variables untouched. Within this setting, we assessed the following cases:

- New TCI values, no limitations

- New TCI values, unchanged annual bed nights

- New TCI values, unchanged monthly bed nights

In the first case the future TCI values according to the RCAO and HIRHAM scenarios were simply filled into the equations. An interesting aspect of this case is that it may reveal something about the net effect of climate change on the number of bed nights in Europe. Some areas will become more attractive, while other regions will become less suitable in some seasons and more or equally suitable in others. The net effect on the overall number of bed nights in Europe is undetermined, but this first case may give a clue of whether climate change induces a positive or a negative change in demand.

Nevertheless, there is some tension between the first case, with variable numbers of bed nights, and the fact that our models are distribution models that do not pay attention to the generation of tourists in the countries of origin. As a result, we have also studied the case in which total annual demand in terms of bed nights remains constant. This second case sheds some light on the effects of relative changes in the climate as expressed by the TCI scores. If conditions in all regions improve (deteriorate), all regions would attract more (less) visitors in case one. By keeping total volumes constant, there are only distributional changes in case two, with tourists moving to the regions with the largest gains (smallest losses) in TCI. It does not 
matter what time of year has the greatest changes; the tourist volumes will follow regardless. Tourists are thus assumed to be fully flexible, and not bound by any institutional or other constraints that would limit their temporal 'window of opportunity'. The phenomenon of ageing in Europe may give this assumption some credibility, as elderly people tend to have more temporal flexibility than younger people in their working lives.

The assumption of full seasonal flexibility is discarded in case three. In this case, not only the total number of bed nights is considered to be fixed, but also the monthly number of bed nights. In other words, the seasonal distribution of bed night volumes is kept constant. This case allows for the assessment of a scenario in which institutional constraints remain firmly in place. Traditionally, school holidays have been important in the holiday planning of many families. Other sectors, such as the construction sector in some countries, can also have periods of forced leave. While such institutional and cultural arrangements are subject to change, in this third case, the institutional influence on tourism seasonality remains strong.

As the spatial unit of analysis the European NUTS 2 region was selected, which in many countries equals a province. The NUTS 2 data that were used for the model are collected by Eurostat (available from the Eurostat website http://epp.eurostat.ec.europa.eu, under General and regional statistics, subheading Regional statistics). The TCI scores obtained in the physical assessment were used to represent regions' climate suitability for tourism. To this end, the gridded TCI data were converted to regional data on the NUTS 2 level, using GIS techniques to link grid points to shapes.

Not all data were available for all NUTS 2 regions in Europe. In particular for some of the new member states, we therefore had to resort to country-level analysis. All in all, the model was developed for a total of 214 regions. To reflect the importance of seasonality, each region-month combination was treated as an individual unit for which tourist activity had to be estimated. As a result, the dataset contained $214 \times 12=2568$ data points for each variable per model, per time slice.

The calculation of the economic results is directly based on the changes in numbers of bed nights. The Eurostat database contains country-level data on total expenditure by foreign tourists. These expenditure figures were divided by the total number of bed nights to arrive at average expenditure per bed night. This figure turned out to vary widely between countries. Of course, expenditure figures do differ between countries as some countries are more expensive than others or offer more expensive types of holidays. It is likely, however, that this is not the only factor at play. There may also be differences in the reporting of the numbers. The high values per tourist night in some of the eastern European countries suggest that a considerable share of visitors use accommodation that is not included in the statistics, either because they stay with friends or family, or because they stay in establishments that do not report their statistics.

\section{Physical assessment}

\subsection{Baseline}

Currently, summer is the best season for most types of outdoor tourism for most if not all countries in Europe. Excellent conditions (in particular for beach tourism) can be found around the Mediterranean sea. This general picture is reproduced by the analysis with the Tourism Climatic Index (TCI).

Both the HIRHAM and the RCAO models reproduce good to ideal conditions in most of continental Europe. The models coincide in evaluating the conditions in parts of Spain, 
Greece and Turkey as ideal, and the general conditions in the south of Europe as excellent. Nevertheless, the findings are clearly distinct for the northern half of Europe. The HIRHAM model produces a picture in which continental Europe is almost entirely red, representing excellent conditions, whereas the RCAO model does not (see Fig. 1). One has to bear in mind that the TCI describes the climatic attractiveness for general outdoor tourism activities, which has lower thermal requirements than, for example, beach tourism.

The RCAO and HIRHAM models produce more similar TCI patterns in the shoulder seasons. The southern half of Europe boasts good to excellent conditions in autumn and in particular spring, whereas in the northern regions of Europe, conditions are acceptable at best. In winter, conditions are unfavourable in the whole of Europe.

A proxy for a region's length of the season that is suitable for general tourism activities can be obtained by counting the average number of months per year with TCI scores above a certain threshold. The example of Mieczkowski (1985) and Amelung and Viner (2006) is followed in using a threshold value of 70. The HIRHAM model produces somewhat more optimistic values for the northern and western parts of Europe, whereas the RCAO model yields better results for Spain, and sections of Italy and other Mediterranean countries. Both models confirm the position of the Mediterranean as Europe's number one position for general outdoor tourism activities.

\subsection{Future}

To assess the impact of climate change on the distribution of climatic resources for Europe, simulated data were fed into the TCI model. The results are presented by time slice (' 2020 s' and '2080s') and by season.

\subsubsection{Changes between the 1970s and the 2020 s}

Although changes between the baseline ('1970s') and the 2020s are modest, certain trends are becoming visible. In all three seasons (winter is disregarded, because conditions remain unfavourable in almost the whole of Europe), there is a poleward trend in TCI patterns. In spring and autumn, these changes are small, but they are positive in most areas of Europe. Changes are most significant in the Mediterranean region, where the area with very good to ideal conditions increases. In more northern regions, conditions improve but remain acceptable at best. In summer, changes are mixed. In the interior of Spain and Turkey, in
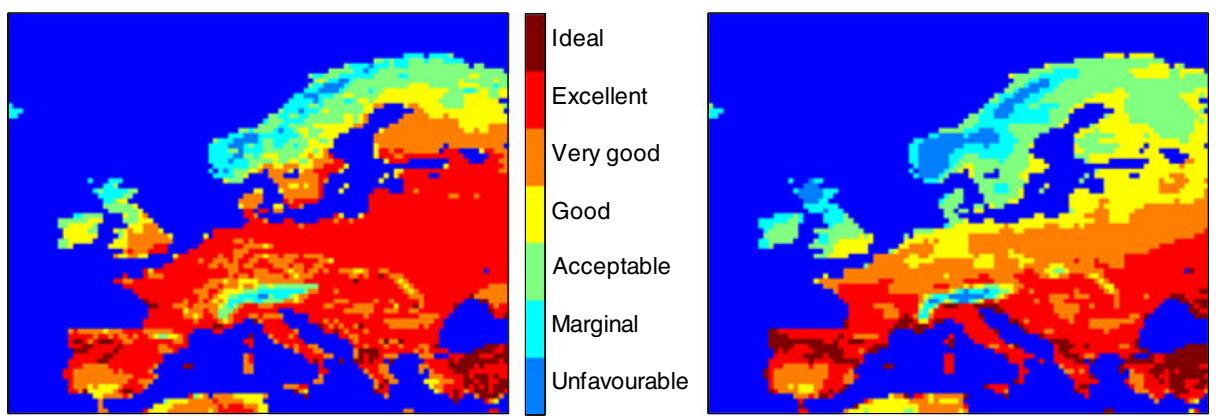

Fig. 1 Baseline climatic conditions for tourism in summer in the period 1961-1990 ('1970s'), according to the HIRHAM model (left) and the RCAO model (right) 
parts of Italy and Greece, and in the Balkans, conditions deteriorate. In the northern and western parts of Europe, however, TCI scores increase.

\subsubsection{Changes between the 1970s and the 2080 s}

By the end of the 21st century, the distribution of climatic resources in Europe is projected to change significantly. All four model-scenario combinations agree on this, but the magnitude of the change and the evaluation of the initial conditions differ.

For the spring season, all model results show a clear extension towards the north of the zone with good conditions. Compared to the RCAO model, the HIRHAM model projects relatively modest changes. In the HIRHAM-A2 scenario, spring conditions will have become very good to excellent in most of the Mediterranean by the end of the century. Good conditions are projected to be more frequent in France and the Balkans. The same tendency is visible in the B2 scenario, albeit at a slower pace.

The direction of change in the RCAO model runs is similar, but its magnitude is much larger. Excellent conditions, which are mainly found in Spain in the baseline period, will have spread across most of the Mediterranean coastal areas by the 2080s. In the northern part of continental Europe, conditions improve remarkably as well, from being marginal to good and even very good.

In summer, the zone of good conditions also expands towards the North, but this time at the expense of the south. In the HIRHAM model runs (see Fig. 2), conditions will become excellent throughout the northern part of continental Europe, as well as in Finland, southern Scandinavia, southern England and along the eastern Adriatic coast. At the same time, climatic conditions in southern Europe deteriorate enormously. In parts of Spain, Italy,
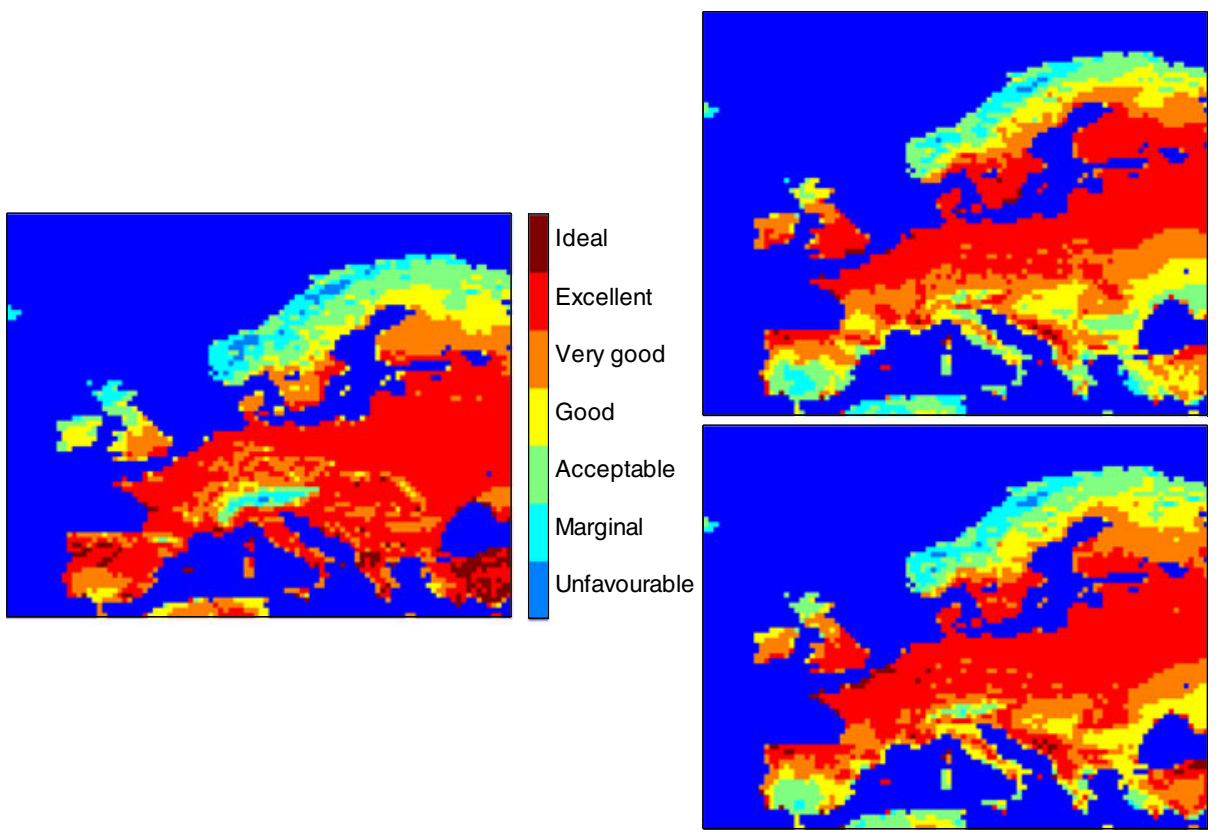

Fig. 2 TCI scores in summer in the 1970s (left) and the 2080s (right), according to the HIRHAM model, A2 (top) and B2 (bottom) scenarios 
Greece, and Turkey, TCI scores in summer go down by tens of points, sometimes dropping from excellent or ideal (TCI>80) conditions to marginal conditions (TCI between 40 and 50).

These summertime losses are even larger, and more extensive geographically in the RCAO model runs (see Fig. 3). In the B2 scenario, much of the Mediterranean, and in the A2 scenario even much of the southern half of Europe loses dozens of TCI points, ending up in the marginal-good range, down from the very good-ideal range the region was in during the 1970s. Interestingly, according to the RCAO model, the changes are so quick that the belt of optimal conditions will move from the Mediterranean all the way up to the northern coasts of the European continent and beyond. In the A2 scenario, excellent conditions can only be found in a very narrow coastal area, stretching from the North of France to Belgium and the Netherlands, and in some coastal areas in Poland. According to these results, the improvement in conditions in the northern half of Europe may be shortlived, although the UK and Scandinavia may have more time to benefit.

Changes in autumn are more or less comparable to the ones in spring. TCI scores improve throughout Europe, with excellent conditions covering a larger part of southern Europe and the Balkans. TCI scores in the northern parts of Europe remain lower than in the south, but the improvements are significant. Large areas attain good conditions (in the HIRHAM model, up from acceptable ones) or acceptable conditions (in the RCAO model, up from marginal ones).

Projected changes in winter are of much less interest than the changes in other seasons, as most of Europe is and will remain unattractive for general tourism purposes (this is not the case for winter sports) in winter. There are some changes, however, in the southernmost areas in Europe. In particular in the south of Spain, conditions are projected to improve from being unfavourable to marginal or even acceptable.
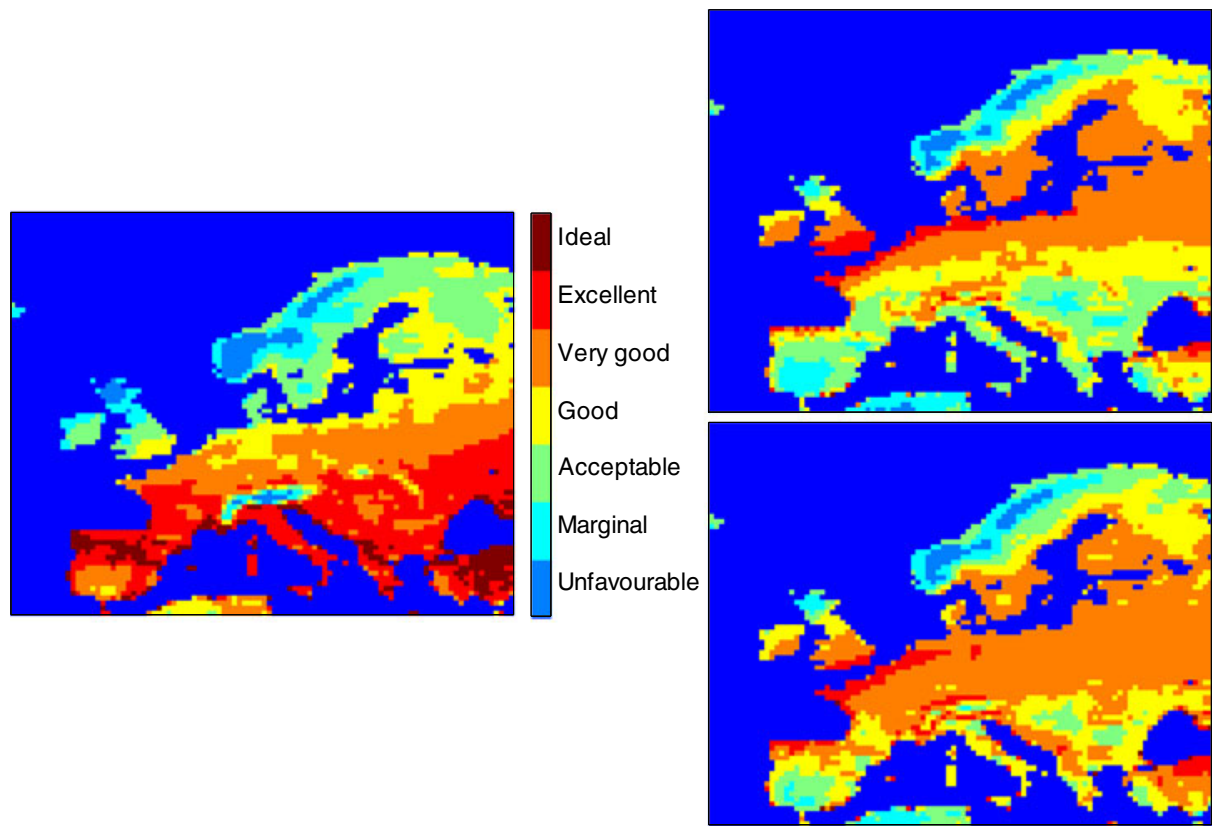

Fig. 3 TCI scores in summer in the 1970s (left) and the 2080s (right), according to the RCAO model, A2 (top) and B2 (bottom) scenarios 


\subsubsection{Changes in seasonality}

The changes that have been discussed above have significant implications for the length of the 'holiday season' (in a climatic sense) in Europe. This season length is defined here as the number of months with very good conditions (TCI $>70$ ), as described above. Currently, southern Europe has significantly more good months than northern Europe. Under the influence of climate change, this is projected to change, however. In both the HIRHAM and the RCAO models, season length will become much more evenly distributed across Europe. The dominant trend in southern Europe is a decrease in good months in summer, whereas in northern Europe there will be an increase in good months in summer, spring and autumn. Interestingly, a coastal strip in southern Spain and Portugal is projected to maintain or even increase (HIRHAM-A2) its current season length.

\section{Economic assessment}

\subsection{Baseline model}

Separate equations were estimated by ordinary least squares (OLS) for the two TCI datasets: one for the RCAO-based dataset and one for the HIRHAM-based dataset. The following econometric equation gave the best result for the HIRHAM dataset (with t-values in brackets):

$$
\begin{aligned}
\ln \text { BedNights }= & 5.77(11.03)+0.41 \ln T C I(8.03)+2.67 \ln G D P(13.55)-0.80 \ln C P I(-11.11) \\
& -0.97 m 1(-14.93)-0.95 m 2(-15.65)-0.77 m 3(-13.42)-0.75 m 4(-13.88) \\
& -0.42 m 5(-8.44)-0.40 m 6(-8.37)+0.03 m 8(0.60)-0.32 m 9(-6.74) \\
& -0.51 m 10(-9.71)-0.94 m 11(-15.28)-0.89 m 12(-13.49)
\end{aligned}
$$

in which BedNights stands for the number of bed nights, TCI reflects the score on the Tourism Climatic Index, GDP stands for Gross Domestic Product, CPI refers to the consumer price index, and $m 1 \ldots m 12$ are the months of the year. Variable $m 7$ was dropped to avoid multicollinearity.

The following equation gave the best result for the RCAO dataset (with t-values in brackets):

$$
\begin{aligned}
\ln \text { BedNights }= & 2.83(5.82)+1.01 \ln T C I(25.67)+2.34 \ln G D P(12.01)-0.59 \ln C P I(-8.30) \\
& -0.05 m 2(-1.02)+0.02 m 3(0.47)-0.08 m 4(-1.58)+0.15 m 5(2.86) \\
& +0.08 m 6(1.39)+0.45 m 7(7.82)+0.51 m 8(8.96)+0.26 m 9(4.82) \\
& +0.30 m 10(6.13)-0.01 m 11(-0.11)+0.03 m 12(0.57)
\end{aligned}
$$

in which variable $m 1$ was dropped to avoid multicollinearity.

\subsection{Simulating the future}

Results were calculated for each of the 2568 region-month combinations. In this section, they are presented in an aggregated form. The results are structured according to the three cases that were discussed in section 2: new TCI values, no limitations; new TCI values, unchanged annual bed nights; new TCI values, unchanged monthly bed nights. The results of the TCI changes according to the RCAO and HIRHAM models are assessed for these three cases, for both scenario A2 and B2. 


\subsubsection{Case 1: New TCI values, no limitations}

A2 scenario The A2 scenario is one of rapid climate change, in which considerable changes in climatic suitability for tourism occur. These changes were more modest for the HIRHAM model than for the RCAO model.

Based on the equations found with the regression analysis, climate change appears to provide a positive stimulus to visitation as expressed in the number of bed nights (see Table 1). The effects in the region-month pairs where TCI values increase are larger than the negative effects in the region-month pairs where TCI values deteriorate. Southern countries such as Spain, Greece, and Croatia face considerable negative consequences, but the positive effects in northern countries, such as the UK, Ireland, Germany, and the Netherlands, and in particular in the central European country of Austria are much larger.

Table 1 Projected changes in the annual number of bed nights (in millions) between 2005 and the 2080s for European countries, based on integrations of the SRES A2 and B2 scenarios and the RCAO and HIRHAM climate models, in case 1: no restrictions in terms of overall tourism volumes (possible climate-induced changes in demand), and full flexibility with respect to holiday planning. The baseline numbers from 2005 (source: Eurostat) have been added for easy reference

\begin{tabular}{|c|c|c|c|c|c|}
\hline & \multicolumn{2}{|c|}{$\mathrm{RCAO}$} & \multicolumn{2}{|c|}{ HIRHAM } & \multirow[t]{2}{*}{2005} \\
\hline & A2 & B2 & A2 & B2 & \\
\hline Austria & 30.4 & 20.9 & 4.5 & 1.9 & 69.7 \\
\hline Belgium & 2.4 & 1.9 & 0.5 & 0.3 & 15.6 \\
\hline Bulgaria & -2.2 & -1.5 & -0.6 & -0.4 & 4.4 \\
\hline Croatia & -7.4 & -4.8 & -1.5 & -0.9 & 33.1 \\
\hline Czech Republic & 3.0 & 2.4 & 0.7 & 0.4 & 19.6 \\
\hline Denmark & 3.0 & 2.2 & 0.6 & 0.4 & 9.4 \\
\hline Estonia & 0.5 & 0.4 & 0.2 & 0.1 & 3.0 \\
\hline Finland & 1.0 & 0.8 & 0.3 & 0.2 & 4.5 \\
\hline France & 3.3 & 6.0 & 1.4 & 1.2 & 108.0 \\
\hline Germany & 6.6 & 5.7 & 1.8 & 1.2 & 48.2 \\
\hline Greece & -4.5 & -3.3 & -1.6 & -1.1 & 40.7 \\
\hline Hungary & -0.2 & -0.1 & 0.0 & -0.1 & 10.8 \\
\hline Iceland & 0.1 & 0.1 & 0.1 & 0.1 & 1.5 \\
\hline Ireland & 5.9 & 4.8 & 1.2 & 0.9 & 19.4 \\
\hline Italy & 0.3 & 1.6 & -0.3 & -0.5 & 148.3 \\
\hline Latvia & 0.4 & 0.4 & 0.1 & 0.1 & 1.6 \\
\hline Lithuania & 0.3 & 0.2 & 0.1 & 0.1 & 1.4 \\
\hline Luxemburg & 0.3 & 0.2 & 0.1 & 0.1 & 2.5 \\
\hline Malta & 1.8 & 1.1 & 0.5 & 0.2 & 7.3 \\
\hline Netherlands & 5.2 & 3.7 & 0.9 & 0.6 & 25.2 \\
\hline Norway & 1.6 & 1.2 & 0.6 & 0.4 & 7.6 \\
\hline Poland & 1.5 & 1.2 & 0.3 & 0.2 & 10.5 \\
\hline Portugal & -1.2 & -0.7 & 0.1 & 0.0 & 25.4 \\
\hline Romania & 0.0 & 0.0 & 0.0 & 0.0 & 2.1 \\
\hline Slovakia & 0.4 & 0.4 & 0.1 & 0.1 & 4.8 \\
\hline Slovenia & 0.1 & 0.1 & 0.1 & 0.1 & 4.3 \\
\hline Spain & -7.7 & -4.2 & -0.3 & -0.6 & 209.5 \\
\hline Sweden & 2.5 & 2.0 & 0.6 & 0.4 & 10.1 \\
\hline UK & 11.7 & 9.1 & 2.4 & 1.8 & 81.0 \\
\hline Total & 59.1 & 51.7 & 12.6 & 7.2 & \\
\hline
\end{tabular}


Millions of additional bed nights are projected there, and billions of euros of extra receipts. Since the physical impacts of climate change are much larger in the RCAO scenario than in the HIRHAM scenario, the changes in visitation and receipts are also larger. The net effect of climate change on total bed nights ranges between 13 million and 59 million extra nights. The financial impact ranges from 4 to 18 billion euros if country-specific ratios (expenditure per bed night) are used, and from 3 to 15 billion euros if the European average ratio is used. Apparently, countries with high revenues per bed night receive a disproportionally high share of the benefits of climate change. Total revenues in the countries considered here totalled 243 billion euros in 2005, indicating that the gains from climate change may be considerable.

Some clear changes are visible in the seasonal distribution of bed nights spent in Europe. Activity in July and August diminishes strongly with a reduction of up to 40 million bed nights in the RCAO world, but the rest of the year more than compensates for this effect, with an increase of close to 100 million bed nights in the RCAO world. In the HIRHAM world, where the climate signal is weaker, the same pattern appears, albeit more modest.

In summary: in this scenario, there are a few countries that face slight losses, but many more countries that face large or very large gains.

B2 Scenario The B2 scenario is one of modest climate change, in which changes in climatic suitability for tourism do occur, albeit to a more limited degree than in the A2 scenario. As in the A2 case, changes were more modest for the HIRHAM model than for the RCAO model.

In virtually all countries, the direction of change is the same for both the A2 and B2 scenarios, with smaller changes in the B2 scenario. France and Italy are major exceptions. In the RCAO world, both countries benefit much more from the B2 scenario than from the A2 scenario. In the HIRHAM world, the relative differences are much smaller. For Spain in the RCAO world, losses in the A2 scenario are nearly twice as high as in the B2 scenario, whereas in the HIRHAM world it is the other way around.

As expected, the B2 scenario results in a smaller increase in the overall number of bed nights than the A2 scenario, in both the HIRHAM and RCAO worlds.

\subsubsection{Case 2: New TCI values, unchanged annual bed nights}

A2 Scenario This case depicts a situation in which total volumes of bed nights remain unchanged. That is to say: different from the first case, climate change in itself does not induce changes in tourism volumes, it only leads to seasonal and geographical redistribution. As a result, this case is one of a 'zero-sum' game: there cannot be only winners. This case therefore paints a very different picture of winners and losers (see Table 2). The UK, Germany, Ireland, and in particular Austria still emerge as strong winners, although the gains are considerably smaller than in the first case. These countries are able to sell millions of additional bed nights, and generate billions of euros of extra revenues. In particular the role of Austria is striking, as this country is projected to have customers for an additional 24 million bed nights.

Spain, Croatia, Italy, and Greece are the countries facing the greatest losses. The improved conditions in spring and autumn cannot fully compensate the deteriorated conditions in summer. In the RCAO world, total tourism volumes decrease by 17 million and 9 million bed nights in Spain and Italy respectively, by the end of the century, resulting in around 3.7 billion euros (Spain) and 1.8 billion euros (Italy) of annual foregone revenues. 
Table 2 Projected changes in the annual number of bed nights (in millions) between 2005 and the 2080s for European countries, based on integrations of the SRES A2 and B2 scenarios and the RCAO and HIRHAM climate models, in case 2: no change in overall tourism volumes (no climate-induced changes in demand), and full flexibility with respect to holiday planning. The baseline numbers from 2005 (source: Eurostat) have been added for easy reference

\begin{tabular}{|c|c|c|c|c|c|}
\hline & \multicolumn{2}{|l|}{ RCAO } & \multicolumn{2}{|c|}{ HIRHAM } & \multirow{2}{*}{$\begin{array}{l}\text { Reference } \\
2005\end{array}$} \\
\hline & A2 & B2 & $\mathrm{A} 2$ & B2 & \\
\hline Austria & 23.9 & 15.7 & 3.4 & 1.3 & 69.7 \\
\hline Belgium & 1.5 & 1.1 & 0.3 & 0.2 & 15.6 \\
\hline Bulgaria & -2.9 & -2.2 & -0.7 & -0.5 & 4.4 \\
\hline Croatia & -9.2 & -6.6 & -2.0 & -1.2 & 33.1 \\
\hline Czech Republic & 1.4 & 1.0 & 0.4 & 0.2 & 19.6 \\
\hline Denmark & 2.1 & 1.5 & 0.4 & 0.3 & 9.4 \\
\hline Estonia & 0.3 & 0.2 & 0.1 & 0.1 & 3.0 \\
\hline Finland & 0.6 & 0.4 & 0.2 & 0.2 & 4.5 \\
\hline France & -4.5 & -1.0 & -0.3 & 0.2 & 108.0 \\
\hline Germany & 3.2 & 2.8 & 1.1 & 0.8 & 48.2 \\
\hline Greece & -6.3 & -5.0 & -2.1 & -1.3 & 40.7 \\
\hline Hungary & -1.0 & -0.8 & -0.2 & -0.2 & 10.8 \\
\hline Iceland & 0.0 & 0.0 & 0.0 & 0.0 & 1.5 \\
\hline Ireland & 4.1 & 3.3 & 0.9 & 0.7 & 19.4 \\
\hline Italy & -9.1 & -6.7 & -2.4 & -1.7 & 148.3 \\
\hline Latvia & 0.2 & 0.2 & 0.0 & 0.1 & 1.6 \\
\hline Lithuania & 0.1 & 0.1 & 0.0 & 0.0 & 1.4 \\
\hline Luxemburg & 0.2 & 0.1 & 0.1 & 0.0 & 2.5 \\
\hline Malta & 1.2 & 0.6 & 0.3 & 0.2 & 7.3 \\
\hline Netherlands & 3.5 & 2.3 & 0.5 & 0.5 & 25.2 \\
\hline Norway & 0.9 & 0.7 & 0.5 & 0.3 & 7.6 \\
\hline Poland & 0.7 & 0.5 & 0.2 & 0.1 & 10.5 \\
\hline Portugal & -2.5 & -1.9 & -0.2 & -0.2 & 25.4 \\
\hline Romania & -0.3 & -0.2 & 0.0 & 0.0 & 2.1 \\
\hline Slovakia & 0.1 & 0.1 & 0.0 & 0.0 & 4.8 \\
\hline Slovenia & -0.2 & -0.1 & 0.0 & 0.0 & 4.3 \\
\hline Spain & -17.4 & -13.0 & -2.7 & -1.9 & 209.5 \\
\hline Sweden & 1.6 & 1.3 & 0.4 & 0.3 & 10.1 \\
\hline UK & 8.0 & 5.9 & 1.7 & 1.4 & 81.0 \\
\hline Total & 0.0 & 0.0 & 0.0 & 0.0 & \\
\hline
\end{tabular}

In the HIRHAM world, the largest declines in bed nights and in revenues are suffered by the same countries, albeit at a much more modest scale.

Changes in the seasonality patterns are similar to those found for case 1 . Visitation in the summer months of July and August (and also in June in the RCAO world and February and March in the HIRHAM world) decreases sharply. This is (by definition) fully compensated by gains in the other months, in particular April, May and October.

B2 Scenario As in case 1, the direction of the changes is almost always the same for both the A2 and B2 scenarios. In France, however, changes are slightly positive in the HIRHAM-B2 scenario, whereas they are slightly negative in the HIRHAM-A2 scenario. This phenomenon is very probably related to the fact that conditions will at first be improving in the northern parts of France and deteriorating in the southern parts, with net 
positive effects at first. As the zone of deteriorated conditions gradually moves northwards, however, the balance eventually tilts towards the negative side. As in the first case, the Nordic countries in general benefit more from climate change in the A2 scenario than in the B2 scenario. This is according to expectations, as conditions in those areas are currently rather cool and not very favourable, and therefore have a lot to gain from climate change. Changes take place at a faster pace in the A2 than in the B2 scenario.

\subsubsection{Case 3: New TCI values, unchanged monthly bed nights}

A2 Scenario This case sketches a situation in which the seasonal visitation patterns remain as they were in the simulated baseline period, i.e. they remain firmly summer peak. As could be expected, this case accentuates the geographical shift of the belt with pleasant summer conditions from the Mediterranean region towards the north (see Table 3). As tourists cannot adapt by vacationing in another season, they are forced to visit other destinations if they decide that the climate in their traditional holiday destination has become unattractive.

The observed trends are roughly the same as the one sketched in case 2. The Scandinavian countries benefit stronger, southern Europe in general loses more heavily. In the RCAO world, Italy and Spain have a decline in annual bed nights of 11 and 22 million bed nights respectively. Their combined losses are of roughly the same magnitude as the gains in the two biggest winners: Austria and the UK. In the HIRHAM world, the changes are much more modest, but Spain and Italy still stand out as by far the largest losers in absolute terms, and Austria as the biggest winner.

B2 Scenario France and Slovakia are the only countries for which changes are positive in one scenario and negative in the other, at least in the RCAO world. France enjoys a small gain in the B2 scenario ( +0.5 million bed nights), and a significant loss in the A2 scenario ( -2.8 million bed nights). Slovakia enjoys a slight increase in bed nights in the B2 scenario and an slight decrease in the A2 scenario. In this case, again, Nordic countries such as Sweden, Finland, Latvia and Estonia benefit much less from the rate of climate change depicted in the B2 scenario than from the rate of change in the A2 scenario. The performance of Austria is very strong in the B2 scenario as well, with a projected 15.4 million additional bed nights.

\section{Conclusions}

This assessment shows that climate change is projected to have significant impacts on the physical resources supporting tourism in Europe. In summer, southern Europe will experience climatic conditions that are less favourable to tourism than the current climate. At the same time, countries in the North, which are the countries of origin of many of the current visitors of the Mediterranean, will enjoy better conditions in summer, as well as a longer season with good weather. In particular in southern Europe, the worsening situation resulting from deteriorating thermal conditions is further aggravated by increasing water shortages. Peak demand from tourism coincides with peak demand from agriculture, residential areas, the energy sector and nature. It also coincides with the summer dip in water supply, which will very likely be deepened by climate change.

The results presented here should be treated very carefully. First of all, thermal comfort is only one environmental issue that will be affected by climate change. Water availability and snow reliability have also been assessed in the PESETA project but not in sufficient 
Table 3 Projected changes in the annual number of bed nights between 2005 and the 2080s for European countries, based on integrations of the SRES A2 and $\mathrm{B} 2$ scenarios and the RCAO and HIRHAM climate models, in case 3: no change in overall tourism volumes (no climate-induced changes in demand), and fixed seasonality. The baseline numbers from 2005 (source: Eurostat) have been added for easy reference

\begin{tabular}{|c|c|c|c|c|c|}
\hline & \multicolumn{2}{|l|}{ RCAO } & \multicolumn{2}{|c|}{ HIRHAM } & \multirow{2}{*}{$\begin{array}{l}\text { Reference } \\
2005\end{array}$} \\
\hline & A2 & B2 & $\mathrm{A} 2$ & B2 & \\
\hline Austria & 23.3 & 15.4 & 3.7 & 1.7 & 69.7 \\
\hline Belgium & 1.4 & 1.0 & 0.2 & 0.2 & 15.6 \\
\hline Bulgaria & -2.3 & -1.8 & -0.6 & -0.4 & 4.4 \\
\hline Croatia & -7.3 & -5.1 & -1.5 & -0.9 & 33.1 \\
\hline Czech Republic & 0.7 & 0.6 & 0.3 & 0.2 & 19.6 \\
\hline Denmark & 3.3 & 2.1 & 0.5 & 0.3 & 9.4 \\
\hline Estonia & 0.3 & 0.2 & 0.1 & 0.1 & 3.0 \\
\hline Finland & 0.7 & 0.5 & 0.2 & 0.2 & 4.5 \\
\hline France & -2.8 & 0.5 & 0.3 & 0.5 & 108.0 \\
\hline Germany & 2.2 & 2.2 & 0.9 & 0.7 & 48.2 \\
\hline Greece & -5.2 & -4.3 & -1.9 & -1.3 & 40.7 \\
\hline Hungary & -1.4 & -1.0 & -0.3 & -0.2 & 10.8 \\
\hline Iceland & 0.2 & 0.1 & 0.1 & 0.0 & 1.5 \\
\hline Ireland & 4.5 & 3.3 & 0.8 & 0.6 & 19.4 \\
\hline Italy & -11.1 & -7.8 & -2.6 & -1.8 & 148.3 \\
\hline Latvia & 0.2 & 0.2 & 0.0 & 0.1 & 1.6 \\
\hline Lithuania & 0.2 & 0.1 & 0.0 & 0.0 & 1.4 \\
\hline Luxemburg & 0.2 & 0.1 & 0.1 & 0.0 & 2.5 \\
\hline Malta & 0.8 & 0.4 & 0.3 & 0.1 & 7.3 \\
\hline Netherlands & 3.8 & 2.3 & 0.5 & 0.4 & 25.2 \\
\hline Norway & 1.7 & 1.1 & 0.6 & 0.4 & 7.6 \\
\hline Poland & 0.5 & 0.4 & 0.1 & 0.1 & 10.5 \\
\hline Portugal & -3.1 & -2.4 & -0.4 & -0.3 & 25.4 \\
\hline Romania & -0.3 & -0.3 & -0.1 & 0.0 & 2.1 \\
\hline Slovakia & -0.1 & 0.1 & 0.0 & 0.0 & 4.8 \\
\hline Slovenia & -0.3 & -0.2 & 0.0 & 0.0 & 4.3 \\
\hline Spain & -21.6 & -15.6 & -3.4 & -2.3 & 209.5 \\
\hline Sweden & 2.7 & 1.8 & 0.6 & 0.4 & 10.1 \\
\hline UK & 8.8 & 6.0 & 1.5 & 1.2 & 81.0 \\
\hline Total & 0.0 & 0.0 & 0.0 & 0.0 & \\
\hline
\end{tabular}

depth to merit incorporation in this paper. Landscape, biodiversity, beach erosion, and deterioration of monuments are just a few examples of other factors that are affected by climate change, but are not assessed in the scope of the PESETA project.

Secondly, in particular the analyses of the changes in TCI conditions are of a very general nature. Different tourism segments have very different climate requirements. The general approach taken here provides a first-order assessment, but more refined approaches will be needed in future studies. A more detailed analysis would require an appropriate level of insight into tourists' climate requirements, which relate to the third point of caution. Currently, our understanding of tourists' preferences with respect to climate and weather conditions remains very limited. Preferences are known to differ between tourism activities, and may also differ between tourists from different countries and cultures, but more empirical research is needed before segment-specific assessments can be done. Finally, 
there is still considerable uncertainty in our understanding of the climate system. In this assessment, different models and scenarios were used to cover part of this uncertainty range. The analyses showed that the use of multiple models and scenarios was appropriate. The results from the HIRHAM and the RCAO model differed considerably, although they generally coincided in the direction of change they predicted.

In this paper we report on the modelling efforts to explore the effects of climate change on tourism visitation and expenditure in Europe. The results suggest that these effects may be very significant in the longer term. No assessment was made of the changes up to the 2020 s, as the physical impact assessment revealed relatively small changes, the significance of which is highly questionable given the uncertainties involved.

No attempt was made to model the changes in tourism in the course of this century. The uncertainties in doing this were considered too large, and it would only distract from the purpose of the study. Therefore, all variables were left unchanged except for the climate, as expressed by the Tourism Climatic Index TCI.

A new insight of our analysis is that climate change may have a net positive effect on the overall European potential for tourism: up to 59 million bed nights more or some $8 \%$ of the total of 777 million nights registered for 2005 in the NUTS2 regions we examined. Additional potential revenues could be in the order of 4-18 billion euros.

As the analysis of the physical impacts already suggested, however, the changes are likely to be unequally spread across Europe. The year-round potential for tourism increases most in the northern parts of Europe, including the UK, Germany, the Netherlands and Scandinavia, and in Austria. In particular the large gains projected for Austria are striking, but they can be explained from a number of key factors. To start with, Austria is projected to experience large gains in TCI scores. In addition, Austria is already a very important tourism destination, not only in winter but also in summer. Therefore, the country has high initial values for the number of bed nights and revenues. Nevertheless, the important position of the winter sports industry in Austria is a good reason to treat the results with care, as winter sports are not covered by the TCI analyses. As a result, the positive results for Austria are likely to be an overestimation. In the southern countries, there is evidence for a net loss of potential, although improvements in the spring and autumn seasons are likely to offset a significant share of the deteriorations in summer.

Hamilton et al. (2005) clearly show that changes in potentials are not enough to project changes in visitation. The destination's conditions relative to those of competing areas play a crucial role as well. Looking at the changes in these relative positions, the picture changes significantly. Climate change no longer induces a growth in overall tourism volumes, but leads to a redistribution of visitation. Visitation, as expressed by the number of bed nights, is shown to increase significantly in Austria, the UK, Germany, the Netherlands, Belgium, Ireland, Scandinavia and other countries in the northern parts of Europe, at the expense of southern European countries such as Spain, Italy and Greece. In particular Austria and the UK enjoys significant gains in relative terms, whereas Italy and Spain face the largest losses. Up to 53 million bed nights a year may be redistributed across European countries because of changes in relative conditions, equivalent to some 14 billion euros of expenditure.

In the above assessments, the assumption is made that tourism volumes (i.e. bed nights) can be freely redistributed based on changes in relative climate suitability. Adaptation can occur in spatial terms (other destination) or in temporal terms (other season) or both. The assumption of full temporal flexibility is likely to be too loose. Although ageing and shorter working hours may increase flexibility among a sizable share of the tourist population, school holidays and other institutional factors are unlikely to lose their significance altogether. To explore the possible impact of rigid institutional arrangements, we also 
considered the scenario in which overall monthly tourist volumes are fixed, so that no temporal substitution can take place. While this assumption is very rigid, it provides some insight into the sensitivity of the results to the level of institutional rigidity. As could be expected, the redistribution of tourist volumes is even larger than in the situation of full seasonal flexibility: up to 55 million bed nights a year (around $10 \%$ of current volumes), worth 14 billion euros. Austria and the UK are by far the greatest winners in absolute numbers: +23.3 million and +8.8 million bed nights respectively in the RCAO-A2 world, and +1.7 million and +1.2 million bed nights respectively in the HIRHAM-B2 world. Spain and Italy have most to loose: -21.6 million and -11.1 million bed nights respectively in the RCAO-A2 world, and -2.3 million and -1.8 million bed nights respectively in the HIRHAM-B2 world.

The results presented must be treated with great care, as the uncertainties are very large. The predictive value of the models is not very large, suggesting that important determinants may be missing. The importance of some of these can be guessed, as was discussed in the text. Among other things, no institutional variables were included as no suitable data were available, although summer holidays and other institutional rigidities are known to have a significant effect on holiday patterns. The same goes for distance and travel costs. As no origin-destination flows of tourists could be established, attention was focused on the destination side, leaving the generation of tourists in the regions of origin unexplained, and the distances travelled unaccounted for.

In addition to the missing variables, the quality of the data used is sometimes uncertain. Different countries may use different methods for collecting statistics and aggregating them, and may have different levels of participation by the side of the tourist industry. For example, there were very large differences between the average receipts per tourist night, which could not be explained by the differences in price levels and wealth between countries.

Importantly, this study has only considered spatial and temporal adaptation by tourists, ignoring other options available to tourists (e.g. staying inside), and adaptation options available to the tourist industry and other stakeholders. Tourism businesses and destinations may try to reduce their vulnerability to climate change by offering a diverse set of holiday activities, by trying to develop all-year tourism, by developing less climate-dependent types of tourism, or by taking technical measures such as installing air conditioning. None of these adaptation options have been taken into account, as there are currently no methods available to model their effects. Because of this omission, the impacts of climate change on tourism in Europe may well have been overestimated.

Despite the uncertainties involved, however, this report adds to the evidence suggesting that climate change may have a large effect on tourism in Europe, leading to the redistribution of millions if not tens of millions of bed nights, and billions if not tens of billions of euros worth of revenues a year.

Open Access This article is distributed under the terms of the Creative Commons Attribution Noncommercial License which permits any noncommercial use, distribution, and reproduction in any medium, provided the original author(s) and source are credited.

\section{References}

Agrawala S (2007) Climate change in the European Alps: Adapting winter tourism and natural hazards management. Organisation for economic Co-operation and development (OECD), Paris 
Amelung B, Moreno A, Scott D (2008) The place of tourism in the IPCC fourth assessment Report: a review. Tour Rev Int 12:5-12

Amelung B, Nicholls S, Viner D (2007) Implications of global climate change for tourism flows and seasonality. J Travel Res 45(3):285-296

Amelung B, Viner D (2006) Mediterranean tourism: Exploring the future with the tourism climatic index. J Sustain Tour 14(4):349-366

Christensen JH, Christensen OB (2007) A summary of the PRUDENCE model projections of changes in European climate by the end of this century. Clim Chang 81:7-30

Christensen OB, Goodess CM, Ciscar JC (this issue) Methodological framework of the PESETA project on the impacts of climate change in Europe. Climatic Change

Ciscar JC, Iglesias A, Feyen L, Goodess CM, Szabó L, Christensen OB, Nicholls R, Amelung B, Watkiss P, Bosello F, Dankers R, Garrote L, Hunt A, Horrocks L, Moneo M, Moreno A, Pye S, Quiroga S, van Regemorter D, Richards J, Roson R, Soria A (2009) Climate change impacts in Europe. Final report of the PESETA research project. EUR 24093 EN. Joint Research Centre

Ciscar JC, Iglesias A, Feyen L, Szabó L, Van Regemorter D, Amelung B, Nicholls R, Watkiss P, Christensen OB, Dankers R, Garrote L, Goodess CM, Hunt A, Moreno A, Richards J, Soria A (2011) Physical and economic consequences of climate change in Europe. Proc Natl Acad Sci USA 108:2678-2683. doi:10.1073/pnas. 1011612108

De Freitas CR (1990) Recreation climate assessment. Int J Climatol 10:89-103

De Freitas CR, Scott D, McBoyle G (2008) A second generation climate index for tourism (CIT): specification and verification. Int J Biometeorol 52:399-407

Hamilton JM, Maddison D, Tol RSJ (2005) Climate change and international tourism: A simulation study. Glob Environ Chang 15(3):253-266

Lise W, Tol RSJ (2002) Impact of climate on tourist demand. Clim Chang 55(4):429-449

Maddison D (2001) In search of warmer climates? The impact of climate change on flows of British tourists. Clim Chang 49(1/2):193-208

Higham J, Hall CM (2005) Making tourism sustainable: the real challenge of climate change? In: Hall M, Higham J (eds) Tourism, Recreation and Climate Change. Channel View Publications, London, UK, pp 301-307

Mieczkowski Z (1985) The tourism climatic index: A method of evaluating world climates for tourism. Can Geogr 29(3):220-233

Nicholls S, Amelung B (2008) Climate change and tourism in Northwestern Europe: Impacts and adaptation. Tour Anal 13(1):21-31

Rotmans J, Hulme M, Downing TE (1994) Climate change implications for Europe. Glob Environ Chang 4 (2): $97-124$

Scott D, McBoyle G, Schwartzentruber M (2004) Climate change and the distribution of climatic resources for tourism in North America. Clim Res 27(2):105-117

Todd G (2003) WTO Background paper on climate change and tourism. In: Proceedings of the First International Conference on Climate Change and Tourism, Djerba, Tunisia, April 9-11, pp. 19-41

UNWTO-UNEP-WMO (2008) Climate change and tourism: Responding to global challenges. UNWTOUNEP, Madrid, Spain 